well put young people at an unacceptable risk. A young person most likely needs higher absolute values to qualify for safe resection; in other words, a 25 -yr-old patient with $20 \%$ ppo function for FEV1 has much more unhealthy lungs than a 70yr-old patient with a ppo value of $30 \%$, although in absolute values they both have $0.9 \mathrm{~L}$.

The current use of percent of predicted values has been shown to work well and, generally speaking, guidelines should suggest cut-off values which err on the side of safety. The trend to include more patients with marginal cardio-pulmonary functional reserves for resection will continue [4], but must be based on evidence.

\section{C.T. Bolliger*, A. Brunelli" ${ }^{*}$ and A. Charloux}

*Internal Medicine, University of Stellenbosch, Faculty of Health Sciences, Cape Town, South Africa, "Dept of Thoracic Surgery, Umberto I Regional Hospital, Ancona, Italy, and "Physiologie et Explorations Fonctionnelles, Hôpitaux Universitaires de Strasbourg, Strasbourg, France.
Correspondence: C.T. Bolliger, Internal Medicine, University of Stellenbosch, Faculty of Health Sciences; 7505 Tygerberg, Cape Town, South Africa, 75505. E-mail: ctb@sun.ac.za

Statement of Interest: None declared.

\section{REFERENCES}

1 Brunelli A, Charloux A, Bolliger CT, et al. ERS/ESTS clinical guidelines on fitness for radical therapy in lung cancer patients (surgery and chemo-radiotherapy). Eur Respir J 2009; 34: 17-41.

2 Bolliger CT, Perruchoud AP. Functional evaluation of the lung resection candidate. Eur Respir J 1998; 11: 198-212.

3 Quanjer PH, Tammeling GJ, Cotes JE, et al. Lung volumes and forced ventilator flows. Report Working Party Standardization of Lung Function Tests. European Community for Steel and Coal. Official Statement of the European Respiratory Society. Eur Respir J 1993; 6: Suppl. 16, S5-S40.

4 Bolliger CT. Functional reserve before lung resection. How low can we go? Respiration. 2009; 78: 20-22.

DOI: $10.1183 / 09031936.00187109$

\title{
Assessment of linezolid efficacy and safety in MDR- and XDR-TB: an Indian perspective
}

\section{To the Editors:}

We read with interest the analysis of the efficacy, tolerability and safety profile of linezolid in multidrug-resistant (MDR) and extensively drug-resistant (XDR) tuberculosis (TB) in the retrospective TBNET (Tuberculosis Network European Trials group) study by MigLIORI et al. [1]. Before this publication, scattered case reports and small case series have been the only source of data on the efficacy and safety of this drug in the treatment of MDR- and XDR-TB cases.

Linezolid is the first oxazolidinone to be developed and introduced in clinical use. In vitro studies have shown good activity against different species of mycobacteria, including resistant strains. The linezolid minimum inhibitory concentration to inhibit the growth of $90 \%$ of organisms for Mycobacterium tuberculosis is in the range of $1-2 \mathrm{mg} \cdot \mathrm{L}^{-1}$ [2]. However, clinical experience with the use of linezolid in the management of mycobacterial infection is still sparse.

The use of linezolid is especially relevant in a country like India, which bears the burden of a third of the world's MDRTB patients. The most recent, i.e. fourth, World Health Organization global resistance report, released in February 2008, estimated there were 110,132 cases of MDR-TB from India in 2006. This accounted for $20 \%$ of the world's MDR-TB burden. Between them, India and China accounted for $50 \%$ of the global MDR-TB burden [3].

Acquired drug resistance, not just to isoniazid and rifampicin, but also to other second-line drugs is also common in India and XDR-TB strains have been increasingly reported since the first report from India was published in 2007 [4]. Physicians increasingly need to fall back on newer (Group V) and experimental drugs in order to make up the minimum recommended number of active drugs (ideally four or five) to ensure a successful regime. Linezolid has been increasingly used in this role. It is relatively cheap, available off-patent and there are currently 10 generic preparations available in the Indian market. Little is known about its efficacy or toxicity in the Indian context.

We report our clinical experience with the use of linezolid in a cohort of 78 Indian MDR- and XDR-TB patients (36 males and 42 females) being treated at the chest outpatient department of a large private tertiary referral hospital in Mumbai (India). In this prospective, non-randomised study from 2000 to 2007, 18 out of the 78 patients received linezolid. Of these 18 patients, seven harboured XDR-TB and 11 were MDR-TB patients. The mean duration of therapy with the drug was as long as 20.6 months. All 18 patients received the drug only in a dose of $600 \mathrm{mg}$, once a day. Of these 18 cases, 11 patients were cured, four failed treatment and three were lost to follow-up. In our cohort, the use of linezolid was not associated with any difference in treatment outcome.

In comparison with the TBNET cohort (table 1), we noticed a higher incidence of major adverse reactions (61\%) in our patients. Chief among these was a severe peripheral neuropathy. 16 patients were affected by sensory-motor neuropathy. 
TABLE 1 Comparison of the TBNET cohort (MigLIORI et al. [1]) and the present (Udwadia) cohort

\begin{tabular}{|c|c|c|}
\hline Study design & Retrospective & Prospective \\
\hline Setting & $\begin{array}{l}\text { Centres: multicentre; } 21 \text { participating centres } \\
\text { in Belarus, Germany, Italy and Switzerland }\end{array}$ & $\begin{array}{l}\text { Single centre: the chest outpatient department } \\
\text { of a single, large, private, tertiary referral hospital } \\
\text { in Mumbai, India }\end{array}$ \\
\hline Sex & Not mentioned & 36 male, 42 female \\
\hline Linezolid arm & 85 out of 195 patients & 18 out of 78 patients \\
\hline MDR-TB & $41(91.1 \%)$ out of 45 & $11(61.1 \%)$ out of 18 \\
\hline XDR-TB & $4(8.9 \%)$ out of 45 & $7(38.8 \%)$ out of 18 \\
\hline Methodology & $\begin{array}{l}\text { Retrospective, nonrandomised, unblinded, } \\
\text { study evaluating the safety and tolerability of } \\
\text { linezolid at } 600 \mathrm{mg} \text {, once a day or twice a day, } \\
\text { in MDR-/XDR-TB treatment. Efficacy evaluation compared } \\
\text { end-points of } 45 \text { linezolid-treated against } 110 \\
\text { linezolid-nontreated cases }\end{array}$ & $\begin{array}{l}\text { Prospective, nonrandomised addition of linezolid } \\
\text { to the treatment regimes of } 78 \text { consecutive } \\
\text { MDR- and XDR-TB patients to assess outcome } \\
\text { and safety, } 18 \text { of whom received linezolid }\end{array}$ \\
\hline Linezolid dosage & $\begin{array}{l}600 \mathrm{mg} \text { once a day in } 28 \text { patients, } 600 \mathrm{mg} \\
\text { twice a day }\left(1200 \mathrm{mg} \cdot \text { day }^{-1}\right) \text { in } 57 \text { patients }\end{array}$ & $600 \mathrm{mg}$ once a day in all patients \\
\hline Linezolid administration time & 32 weeks & 20.6 months \\
\hline Regimen used & Individualised & Individualised \\
\hline Treatment outcome in linezolid group & & $\begin{array}{l}\text { Cured: } n=11 \text {; treatment failure: } n=4 \text {; } \\
\text { lost to follow-up: } n=3\end{array}$ \\
\hline Mean sputum smear conversion & 102 days & \\
\hline Mean culture conversion & 109 days & \\
\hline Cured & 23 subjects & \\
\hline Completed & 13 subjects & \\
\hline $\begin{array}{l}\text { Time duration after which the adverse } \\
\text { effects occurred }\end{array}$ & After 60 days of treatment & Within 1-3 months \\
\hline Main adverse effect & Anaemia in $44 \%$ & Peripheral neuropathy in $38.88 \%$ \\
\hline Conclusions & $\begin{array}{l}\text { Risk of adverse effects but safer dosage } \\
\text { could be prescribed without losing the potential } \\
\text { benefits; use for only the most complicated } \\
\text { MDR/XDR-TB cases [5] }\end{array}$ & $\begin{array}{l}\text { Linezolid proved to be effective but highly toxic in } \\
\text { Indian patients with MDR/XDR-TB. This warrants } \\
\text { extreme caution when this drug is used for } \\
\text { prolong periods of time in MDR/XDR-TB patients }\end{array}$ \\
\hline
\end{tabular}

TBNET: Tuberculosis Network European Trials; MDR-TB: multidrug-resistant tuberculosis; XDR-TB: extensively drug-resistant tuberculosis.

Nerve conduction study was performed in nine of the 16 patients, revealing axonopathy in all cases studied. The adverse event was always affecting the lower limbs. Neuropathy was often disabling and crippling and persisted for several years after stopping the drug. The higher incidence of neuropathy in our series could have been due to the fact that our Indian MDR-TB patients are likely to have been more malnourished than their European counterparts. 16 out of the 18 patients in the linezolid group were malnourished with BMI $<18 \mathrm{~kg} \cdot \mathrm{m}^{-2}$.
One of our patients developed bilateral blindness secondary to a linezolid-induced bilateral optic neuropathy. This developed 3 months after the drug was initiated and reversed completely within 1 month of stopping linezolid. Only one other case report is available in literature documenting optic neuropathy after the use of linezolid [6]. Only one patient developed anaemia severe enough to need transfusion.

In conclusion, linezolid proved to be an effective but highly toxic drug in Indian patients with MDR-TB. We have learned 
to use it with caution, in a dose never exceeding $600 \mathrm{mg}$, once a day, in patients with MDR- and XDR-TB, who have few other drug options. All of our patients were given written instruction on the side-effects that they are likely to encounter and, at each follow-up, these were diligently checked for. In all patients treated with linezolid, clinical, haematological and neurological evaluations are mandatory on a monthly basis, as well as frequent opthalmological tests.

To conclude, the high frequency of adverse effects to linezolid warrants extreme caution when this drug is used for prolonged periods of time in MDR-TB patients. Thus, prospective, randomised and multicentre evaluations are needed in order to test the efficacy of linezolid as well as the short- and long-term tolerability of the drug in TB patients.

\section{Z.F. Udwadia, T. Sen and G. Moharil}

Dept of Pulmonary medicine, P.D.Hinduja National Hospital and Medical Research Centre, Veer Savarkar Marg, Mahim, Mumbai, India.

Correspondence: Z.F. Udwadia, Dept of Pulmonary Medicine, P.D.Hinduja National Hospital And Medical Research Centre. Veer Savarkar Marg, Mumbai, Maharashtra, 400016, India. E-mail: zfudwadia@gmail.com

Statement of Interest: None declared.

\section{REFERENCES}

1 Migliori GB, Eker B, Richardson MD, et al. A retrospective TBNET assessment of linezolid safety, tolerability and efficacy in multidrugresistant tuberculosis. Eur Respir J 2009; 34: 387-393.

2 Alcala L, Ruiz-Serrano MJ, Perez-Fernandez Turegano C, et al. In vitro activities of linezolid against clinical isolates of Mycobacterium tuberculosis that are susceptible or resistant to first-line antituberculous drugs. Antimicrob Agents Chemother 2003; 47: 416-417.

3 World Health Organization. Anti-tuberculosis drug resistance in the world: The WHO/IUATLD Global Project on Anti-Tuberculosis Drug Resistance Surveillance. Geneva, The World Health Organization, 2008.

4 Jain S, Rodrigues C, Mehta A, et al. High prevalence of XDR-TB from a tertiary care hospital in India. PATS 2007; 4: A510.

5 Sotgiu G, Lange C, Richardson MD, et al. Comment on: daily $300 \mathrm{mg}$ dose of linezolid for the treatment of intractable multidrug-resistant and extensively drug-resistant tuberculosis. J Antimicrob Chemother 2009; 64: 879-884.

6 Rucker JC, Hamilton SR, Bardenstein D, et al. Linezolid-associated toxic optic neuropathy. Neurology 2006; 66: 595-598.

DOI: $10.1183 / 09031936.00132009$

\section{From the authors:}

We read with much interest the letter by Z.F. Udwadia and coworkers reporting interesting data on the Indian experience in the treatment of multidrug-resistant (MDR) and extensively drug-resistant (XDR) tuberculosis (TB) with linezolid.

Murine studies performed a decade ago demonstrated efficacy of linezolid and other oxazolidinones against Mycobacterium tuberculosis [1], despite its low early bactericidal activity [2].
Few clinical reports on selected case series have been made available in the recent past for this specific, presently off-label, indication [3-6]. The profile of this drug in the treatment of MDR-/XDR-TB is at present low, as it is included in Group 5, e.g. the group of drugs with limited or substantially unknown activity against $M$. tuberculosis [7, 8].

Preliminary evidence indicated a high toxicity profile for its long-term use at the dose of $600 \mathrm{mg}$ b.i.d., as up to $25-45 \%$ of cases reported severe anaemia and/or thrombocytopenia and peripheral and optic neuropathy [3-6]. The use of the drug is also limited by its high cost, being in the order of $€ 100$ per vial in Western Europe.

The European Respiratory Journal has recently become a forum for discussing potentialities of this drug in the treatment of MDR-/XDR-TB cases by publishing the TBNET (Tuberculosis Network European Trials group) study on 85 cases [5] performed in four European countries (including Belarus in Eastern Europe), the Indian experience presented by Z.F. Udwadia and co-workers from Mumbai, India of 18 cases, and the two case reports of YEW et al. [9] regarding the use of linezolid $800 \mathrm{mg}$ q.d.

The aim of the present study is to discuss the key findings of the TBNET [5] and Indian studies and to draw further conclusions, focusing on the available evidence on linezolid safety.

The table included in the study by Z.F. Udwadia and coworkers was revised, including a statistical comparison between the main results of the two studies whenever possible.

Data were analysed using Stata 9.0 (StataCorp, College Station, TX, USA). Comparisons between proportions were performed using the Chi-squared test; unpaired t-tests were used for continuous variables when appropriate. Differences were considered to be significant when $\mathrm{p}<0.05$.

The comparison between the two studies suggests the following three main conclusions.

Representativeness and study design: the study by Z.F. Udwadia and co-workers was performed at a single tertiary hospital in India, whereas the study by MigLIORI et al. [5] included patient data from more than 20 hospitals in four European countries. Genetic differences between the patient populations could have a role in explaining the different proportions of adverse events found in the two studies. While the European study was retrospective, the Indian one is prospective, allowing for collection of more variables, including, for example, body weight. This allowed the calculation of the body mass index and discussion of the potential role played by malnutrition in increasing the proportion of cases facing adverse events.

Drug dosage, treatment duration and adverse events: the duration of linezolid treatment was longer in the Indian than in the European study (table 1). $600 \mathrm{mg}$ q.d. was prescribed in the Indian study, while either 600 or 1,200 mg was used in the European one. While in the European study the patients who were prescribed $600 \mathrm{mg}$ had significantly fewer major adverse events $(14.3 \%)$, in the Indian study, at the same dosage, the proportion of major side effects was significantly higher than that of the overall sample in Europe (61\% versus $40.4 \%$; $\mathrm{p}<0.001$ ) (table 1). While in Europe anaemia was the main 